\title{
Use of the Fonseca's Questionnaire to Assess the Prevalence and Severity of Temporomandibular Disorders in Brazilian Dental Undergraduates
}

\author{
Kariny NOMURA ${ }^{1}$ \\ Mathias VITTI ${ }^{1}$ \\ Anamaria Siriani de OLIVEIRA ${ }^{2}$ \\ Thaís Cristina CHAVES ${ }^{2}$ \\ Marisa SEMPRINI ${ }^{1}$ \\ Selma SIÉSSERE ${ }^{1}$ \\ Jaime Eduardo Cecilio HALLAK ${ }^{2}$ \\ Simone Cecilio Hallak REGALO ${ }^{1}$
}

${ }^{1}$ School of Dentistry of Ribeirão Preto, University of São Paulo, Ribeirão Preto, SP, Brazil
${ }^{2}$ School of Medicine of Ribeirão Preto, University of São Paulo, Ribeirão Preto, SP, Brazil

This study to assessed the prevalence of signs and symptoms of temporomandibular disorders (TMD) by means of the frequency distribution of data for 218 dentistry students from a Brazilian public university using the Fonseca's questionnaire. The group consisted of 96 men and 122 women, with an average age of 20 years. Of the students, 53.21\% showed some level of TMD: 35.78\% mild TMD 11.93\% moderate and 5.5\% severe. Women were the most affected group, with 63.11\% showing some level of TMD, against $40.62 \%$ of men. When considering only severe TMD, women are approximately 9 times more affected than men. Students with any level of TMD showed marked characteristics: 76.72\% considered themselves tense people; $71.55 \%$ reported to clench or grind their teeth; $65.52 \%$ reported clicking of the temporomandibular joint; 64.66\% reported frequent headache and $61.21 \%$ neck pain. In conclusion, clinical signs and symptoms of TMD can occur in young population and this information is of great importance for the early diagnosis of the dysfunction.

Key Words: temporomandibular disorder, pain, Fonseca’s questionnaire.

\section{INTRODUCTION}

Temporomandibular disorders (TMD) is a collective term that defines a subgroup of painful orofacial disorders, involving complaints of pain on the temporomandibular joint (TMJ) region and fatigue of the craniocervicofacial muscles, especially mastication muscles, limitation of mandible movement and presence of articular clicking. The etiology of TMD has multifactorial causes related to emotional stress, occlusal interferences, mispositioning or loss of teeth, postural changes, dysfunctions of the masticatory musculature and adjacent structures, extrinsic and intrinsic changes on TMJ structure and/or a combination of such factors (1). The
International Association for the Study of Pain (IASP) defines pain as an unpleasant sensorial and emotional experience, associated to real or potential injuries. This concept admits the possibility of non-existence of a direct relationship between tissue damage and pain, and emphasizes the subjectivity in the interpretation of the painful phenomenon. TMD is acknowledged as the main cause of non-dental orofacial pain. Pain is generally located on the masticatory muscles, in the pre-auricular area and TMJs (2).

Due to the high prevalence and variability of the complaints, TMD is diagnosed by associating signs and symptoms, as some characteristics may be frequent even in a non-patient population $(3,4)$. A previous study involving a non-patient population 
showed that $75 \%$ of sample had one TMD sign and $33 \%$ had one TMD symptom (5). TMD signs are present in $50-75 \%$ of the population at some moment in life, whereas an estimated $20-25 \%$ rate exhibit mild symptoms (6). A study involving Brazilian undergraduates (3) evaluated 200 volunteers and concluded that $39 \%$ were TMD-free, $83.60 \%$ had mild, $13.93 \%$ moderate and $2.45 \%$ severe TMD.

Gray et al. (7) assessed the presence of TMD symptoms among 160 complete denture users. The results showed that $43.13 \%$ of the patients had some level of TMD. Considering the whole sample, 56.87\% were classified as having no disorder, $40 \%$ had mild TMD, $1.87 \%$ moderate and $1.26 \%$ severe.

In order to obtain and compare results from different clinical studies, there was a need for using reliable and valid instruments to measure TMD severity within the sample, which consisted of nonpatient volunteers who could present TMD symptoms. The difficulty involved in the identification of etiological factors and the multifactorial effects of the disorder hindered sample standardization (8). Due to the need of simpler assessment procedures that could be widely applicable and standardize research samples involving TMD patients, questionnaires have been created to address the main clinical TMD findings and assign clinical indexes for patient classification in terms of severity levels (9).

According to Oliveira (8), a simple self-administered questionnaire would offer the advantage of faster application and, thus, low cost. This makes epidemiological surveys and treatment follow-up more feasible. An additional advantage is that a selfapplied questionnaire would provide a severity index with less influence from the examiner and less variability in the measures.

This study evaluated, using the Fonseca's questionnaire (Table 1), the prevalence and severity of TMD in undiagnosed Brazilian dental undergraduates. The characterization of volunteers with undiagnosed TMD would help understanding its prevalence in the Brazilian university population.

\section{MATERIAL AND METHODS}

\section{Volunteers}

A total of 218 undergraduates from a Brazilian dental school (96 male; 122 female; mean age $=20$ years) were selected and answered the Fonseca's questionnaire (9). Prior to that, the volunteers received proper instructions about the goals of the research and experimental procedures, risks and benefits, and signed an informed consent form. All subjects diagnosed as having stomatognathic system impairments, being under TMD treatment, presenting orofacial pain or clinical alterations were excluded.

\section{Procedures}

The questionnaire proposed by Fonseca (9) was used to classify TMD severity in the study population because it is highly efficient in obtaining epidemiological data. The Fonseca's questionnaire follows the characteristics of a multidimensional evaluation. It is composed of 10 questions, which include checking for the presence of pain in temporomandibular joint, head, back, and while chewing, parafunctional habits, movement limitations, joint clicking, perception of malocclusion, and sensation of emotional stress. The volunteers were informed that the 10 questions should be answered with "yes", "no" and "sometimes" and that only one answer should be marked for each question. There was no time limit for completion. That way, there would be no reasons for the subjects to give induced answers.

\section{Data Analysis}

The Fonseca's questionnaire contains an anamnestic index, and the volunteers were classified accordingly as having mild TMD, moderate TMD, severe TMD or no-TMD. The authors obtained 95\% reliability and good correlation with Helkimo's index $(r=0.6169 ; \mathrm{p}<0.05)$ (Table 1). For analysis, the answers "yes", "no" and "sometimes" from each questionnaire were tallied and the total was multiplied by the value attributed to each answer: ten, five, and zero, respectively.The final value was compared to the clinical index and the volunteers were classified per TMD degree, (Table 2).

Results were analyzed using the frequency distribution of the questionnaire answers according to the Fonseca's anamnestic index (9). Positive answers ('yes' and 'sometimes') were summed. The percent means were compared between genders and severity degrees by the chi-square test. Significance level was set at 5\%. 


\section{RESULTS}

There was a smaller percentage of volunteers classified as being free of TMD $(p<0.05)$. The percentage of volunteers classified as having mild TMD was significantly higher $(\mathrm{p}<0.05)$ than that of volunteers with other TMD severity level (severe, moderate and non-TMD). Regarding TMD alone, 53.21\% of the subjects had some degree of the disorder, $35.78 \%$ had mild TMD, 11.93\% moderate and 5.5\% severe (Fig.1). Regarding gender versus TMD degree, $40.62 \%$ of the men showed some degree of TMD versus $63.11 \%$ of the women (Fig. 2). Figures 3 and 4 display the total number of positive answers (yes) given to each question of the Fonseca's questionnaire.

Based on the results of interim analyses, the

Table 1. Fonseca's questionnaire.

\begin{tabular}{llll}
\hline Questions & No & Sometimes & Yes \\
\hline
\end{tabular}

1- Is it hard for you to open your mouth?

2- Is it hard for you to move your mandible from side to side?

3- Do you get tired /muscular pain while chewing?

4 - Do you have frequent headaches?

5- Do you have pain on the nape or stiff neck?

6- Do you have earaches or pain in craniomandibular joints?

7- Have you noticed any TMJ clickingwhile chewing or when you open your mouth?

8- Do you clench or grind your teeth?

9- Do your feel your teeth do not articulate well?

10- Do you consider yourself a tense (nervous) person? subjects were divided into 2 groups: with and without TMD. Positive answers in both groups were analyzed by the total percentage and per gender (Fig. 5-8).

\section{DISCUSSION}

The Fonseca's questionnaire (9) allows collecting a large quantity of information in a relatively short period and at low cost, it is easy to understand and has almost no influence from the examiner.

Epidemiologic studies about TMD show that

Table 2 - Clinical index classification - Fonseca (9).

\begin{tabular}{lc}
\hline Total between 0 and 15 points & No TMD \\
Total between 20 and 40 points & Mild TMD \\
Total between 45 and 65 points & Moderate TMD \\
Total between 70 and 100 points & Severe TMD \\
\hline
\end{tabular}

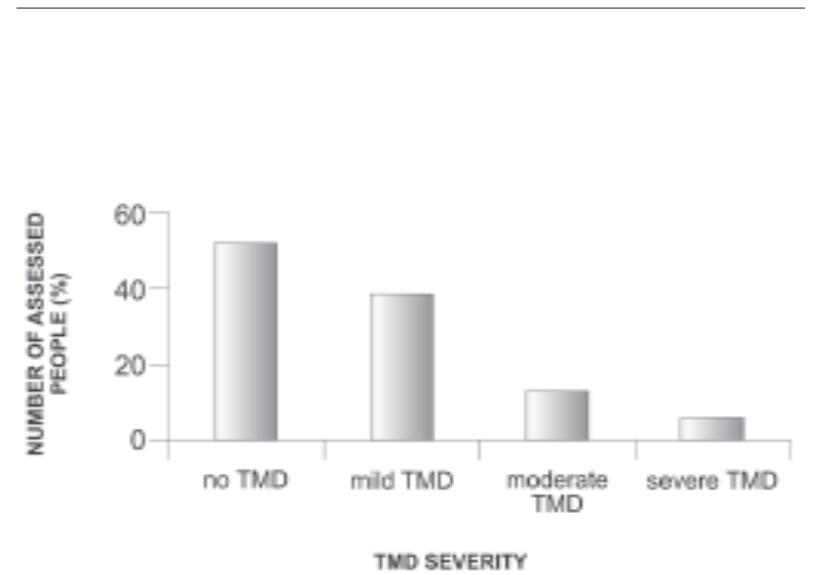

Figure 1. Total number of dental undergraduates evaluated and classified according to TMD severity (\%).

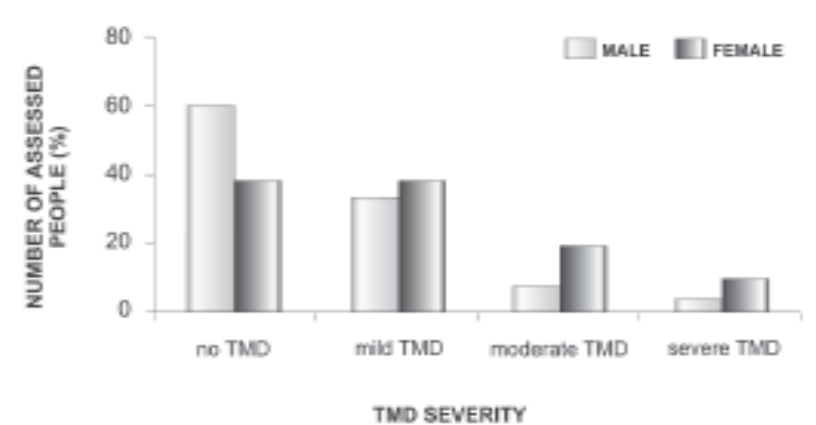

Figure 2. Gender distribution of the dental undergraduates evaluated and classified according to TMD severity (\%). 


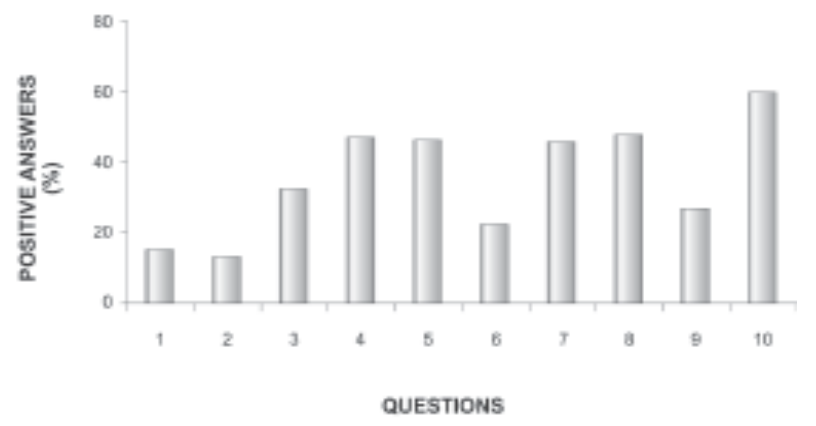

Figure 3. Positive answers (yes) to each of the 10 questions from the Fonseca's questionnaire.

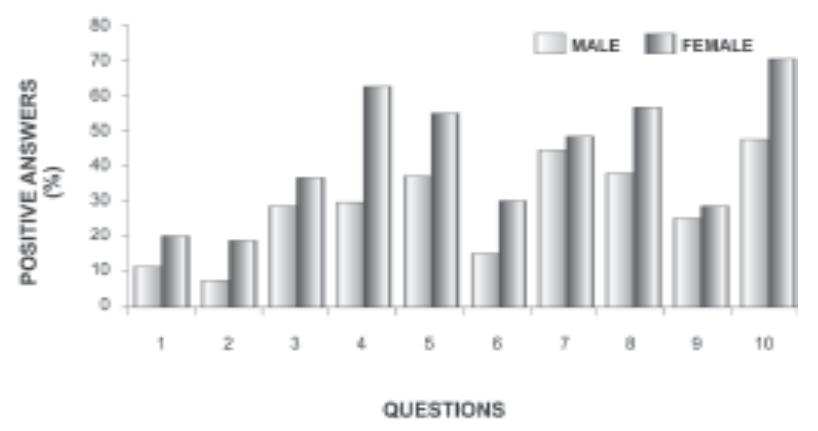

Figure 5. Positive answers (yes) to each of the 10 questions from the Fonseca's questionnaire in both TMD groups, per gender.

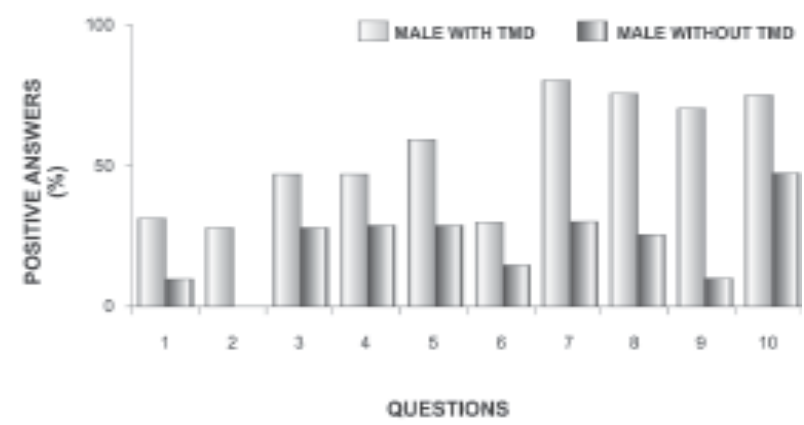

Figure 7. Positive answers (yes) to each of the 10 questions from the Fonseca's questionnaire by men with/without TMD.

which only 6.4\% did not answer "yes" to any of the questions in the Fonseca's questionnaire (9). This adds evidence to the importance of the clinical examination of the stomatognathic system in daily practice (9). $53.21 \%$ of the participants had TMD. These individuals

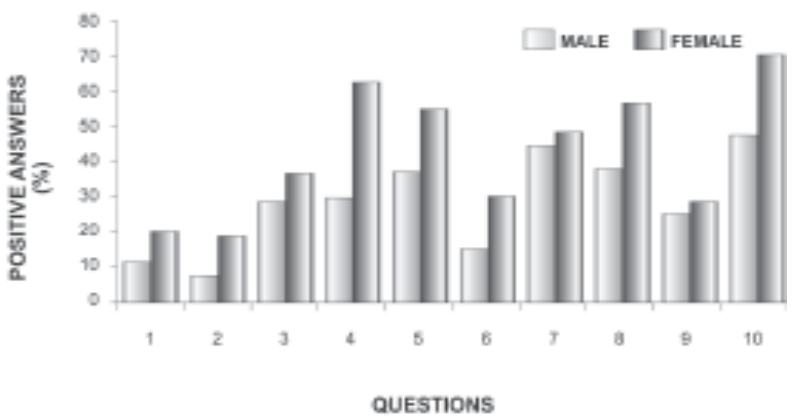

Figure 4. Positive answers (yes) to each of the 10 questions from the Fonseca's questionnaire, per gender.

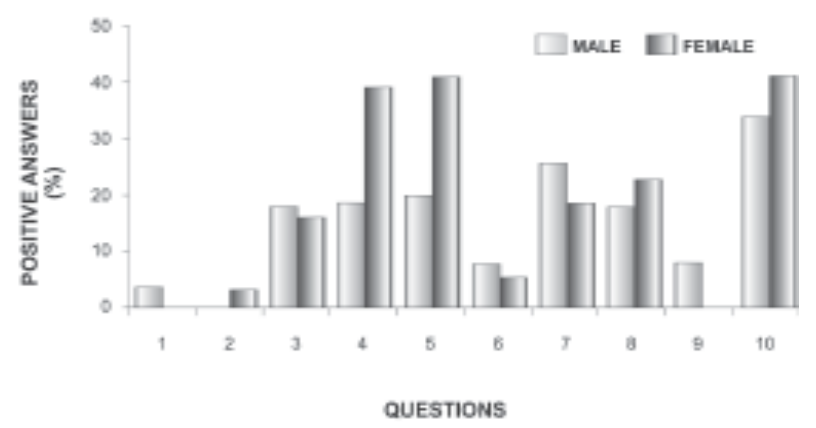

Figure 6. Positive answers (yes) to each of the 10 questions from the Fonseca's questionnaire in both TMD-free groups, per gender.

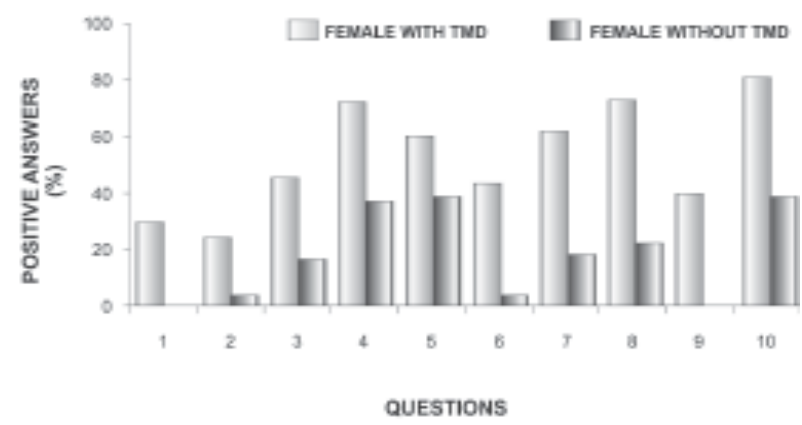

Figure 8. Positive answers (yes) to each of the 10 questions from the Fonseca's questionnaire by women with/without TMD.

approximately $3 / 4$ of the population may have some sign and symptom of disorder at some moment in life (10). Dental occlusion studies have demonstrated a low percentage of individuals who are completely TMDfree. This was also observed in the present study, in 
are dental students, will deal with the stomatognathic system in their professional life, and were unaware that they had TMD. Using a simplified questionnaire, they were able to recognize unnoticed symptoms that could lead to a wear or a greater disorder of the stomatognathic system. The individuals presenting signs and symptoms followed preventive measures, making treatment easier. Garcia et al. (3) obtained similar results. Using the same questionnaire, they found that $61 \%$ of the 200 undergraduates evaluated had some sign of TMD. Pedroni et al. (4) found a prevalence of $68 \%$ of the evaluated volunteers, which is in agreement with the present study. It is estimated that approximately six million Brazilians present TMD signs and symptoms and that most of them do not know they have the disorder, or if treatment is possible and what is the prognosis.

In the present study, over $50 \%$ of the interviewed dental undergraduates had TMD. Women (63.11\%) were the more affected than men (40.62\%). Considering only severe TMD, women were approximately 9 times more affected than men. The high prevalence of TMD in women may be related to their different physiological characteristics, such as regular hormonal variations, muscle structures and different characteristics of the connective tissue $(9,11,12)$.

Students with any level of TMD showed marked characteristics: $76.72 \%$ considered themselves as tense people; $71.55 \%$ reported to clench or grind their teeth; $65.52 \%$ reported TMJ clicking; $64.66 \%$ reported frequent headache and $61.21 \%$ neck pain. These data are of great importance for the early diagnosis of TMD.

In conclusion, a simplified anamnestic index allows identifying a TMD patient and, simultaneously, classifies the patient according to disorder severity. Public health and screening services should adopt the questionnaire, as the anamnestic index may be obtained by technical personnel, in a relatively short period and at low cost, and it has wide population coverage. With proper diagnosis and treatment, this could manage orofacial pain in a large contingent of people.

\section{RESUMO}

Avaliou-se a prevalência de sinais e sintomas de disfunção temporomandibular (DTM) através da distribuição da freqüência de dados obtidos em 218 estudantes de Odontologia da FORP-USP usando o questionário Fonseca. A amostra foi dividida em 96 homens e 122 mulheres (idade média=20 anos). 53,21\% apresentaram algum grau de DTM, sendo 35,78\% DTM leve,
11,93\% moderada e 5,5\% severa. As mulheres foram mais afetadas; $63,11 \%$ apresentaram algum grau de DTM contra $40,62 \%$ dos homens. Considerando somente DTM severa, as mulheres foram cerca de 9 vezes mais afetadas que os homens. Os estudantes com DTM em qualquer grau apresentaram características marcantes como: $76,72 \%$ se consideram pessoas tensas; $71,55 \%$ apertam ou rangem os dentes; 65,52\% têm ruídos na ATM; 64,66\% apresentam dor de cabeça com freqüência e $61,21 \%$ dor na nuca ou torcicolo. Conclui-se que sinais e sintomas de DTM estão presentes em população jovem, sendo estes importantes para o diagnóstico precoce da disfunção.

\section{REFERENCES}

1. LeResche L, Saunders K, Von Korff MR, Barlow W, Dworkin SF. Use of exogenous hormones and risk of temporomandibular disorder pain. Pain 1997;69:153-60.

2. Bonjardim LR, Gavião MB, Pereira LJ, Castelo PM, Garcia RC. Signs and symptoms of temporomandibular disorders in adolescents. Brazilian Oral Research 2005;19:93-98.

3. Garcia AL, Lacerda NJ, Pereira SLS. Evaluation of the degree of dysfunction of the temporomandibular joint and of mandibular movements in young adults. Rev Assoc Paul Cir Dent;51:46-51.

4. Pedroni CR, De Oliveira AS, Guaratini MI. Prevalence study of signs and symptoms of temporomandibular disorder $s$ in university students. J Oral Rehabil 2003;30:283-289.

5. Schiffman E, Fricton JR. Epidemiology of TMJ and craniofacial pain: diagnosis and management. In: The TMJ disorders management of the craniomandibular complex. Kraus SL. ed. New York: Churchill Livingstone; 1998: 23-38.

6. Gray RJ, Davies SJ, Quayle, AA. A clinical approach to temporomandibular disorders. Br Dent J 1994;176:429-435.

7. Gray RJ, McCord JF, Murtaza G, Siddique M. The incidence of temporomandibular disorder signs in patients wearing complete dentures compared to patients with a natural dentition. Eur J Prosthodont Restor Dent 1997;5:99-103.

8. De Oliveira AS, Dias EM, Contato RG, Berzin F. Prevalence study of signs and symptoms of temporomandibular disorder in Brazilian college students. Brazilian Oral Research 2006;20:3-7.

9. Bevilaqua-Grossi D, Chaves TC, de Oliveira AS, MonteiroPedro V. Anamnestic index severity and signs and symptoms of TMD. Cranio 2006;24:112-18.

10. Rugh JD, Solberg WK. Oral health status in the United States: temporomandibular disorders. J Dent Educ 1985;49:398-406.

11. Magnusson T, Egermark I, Carlsson GE. A longitudinal epidemiologic study of signs and symptoms of temporomandibular disorders from 15 to 35 years of age. J Orofac Pain 2000;14:10-19.

12. Celic R, Jerolimov V, Knezovic Zlataric D. Relationship of slightly limited mandibular movements to temporomandibular disorders. Braz Dent J 2004;15:151-54. 